Check for updates

University of Oxford, Oxford OX3 7LD, UK

caroline.struthers@csm.ox.ac.uk Cite this as: BMJ 2020;370:m3593 http://dx.doi.org/10.1136/bmj.m3593 Published: 16 September 2020
CUMBERLEGE REVIEW

\section{Cumberlege review: It's not only drugs and medical devices that can cause harm}

\section{Caroline Struthers senior research fellow}

The recent Cumberlege report, First Do No Harm, ${ }^{12}$ does not consider potential harms to patients from behavioural and psychosocial treatments.

Clinical researchers often have vested interests in the success of interventions they are investigating. They may have already convinced themselves and their peers of their merit. They may have also convinced funders, regulators, policy makers, and insurance companies too. One of the most popular ways to confirm your beliefs and "sell" your favoured treatment is to conduct a randomised trial. Good scientists challenge their own beliefs, however, so trials should always be designed to try to prove that a treatment doesn't work, not to confirm that it does.

There is no incentive for anyone with vested interests, including healthcare providers, to carry out surveillance studies. With non-drug treatments there is also no "yellow card" system to raise the alarm. Systematic reviews are often carried out with input from proponents of the interventions, or even investigators of included studies. If surveillance studies were ever done properly for behavioural and psychosocial treatments (or for drugs and devices, in fact), I suspect they would often reveal lack of long term benefit, and in many cases, evidence of harm. ${ }^{3}$

Prescribing potentially harmful treatments with poor evidence of benefit is unethical. Some treatments, however, particularly behavioural and psychosocial treatments for chronic and poorly understood conditions such as myalgic encephalomyelitis, are politically and organisationally entrenched. There is little interest in research that might challenge their use, such as withdrawal trials or surveillance studies.

Evidence justifying the use of behavioural and psychosocial treatments escapes the greater scrutiny given to research on drugs and medical devices. Patients are disbelieved if they report they have been harmed, and blamed if they don't get better. They are also labelled anti-science if they point out obvious methodological flaws in the studies which have embedded the assumption that these interventions are effective and safe, when they are neither.

\section{Competing interests: None declared.}

Full response at: www.bmj.com/content/370/bmj.m3099/rr-2.

$1 \quad$ Haskell H. Cumberlege review exposes stubborn and dangerous flaws in healthcare. BMJ 2020;370:m3099. doi: 10.1136/bmj.m3099 pmid: 32763955

2 First do no harm: the report of the Independent Medicines and Medical Devices Safety Review. 8 July 2020. www.immdsreview.org.uk/downloads/IMMDSReview_Web.pdf.
3 McPhee G, Baldwin A, Kindlon T, Hughes BM. Monitoring treatment harm in myalgic encephalomyelitis/chronic fatigue syndrome: A freedom-of-information study of National Health Service specialist centres in England. J Health Psychol 2019;.

doi: 10.1177/1359105319854532 pmid: 31234662 